\title{
Aspects of community-acquired Clostridium Difficile infection in Dolj county, România
}

\author{
Livia Dragonu'1,2, Augustin Cupsa1,2, Ana Bobarnac ${ }^{3}$, Florentina Dumitrescu ${ }^{1,2}$, \\ Lucian Giubelan ${ }^{1,2}$, Irina Niculescu ${ }^{1,2}$, Andreea Cristina Stoian', Iulian Diaconescu ${ }^{1,2}$ \\ ${ }^{1}$ University of Medicine and Pharmacy, Craiova, Romania \\ ${ }^{2}$ Hospital for Infectious Diseases and Pneumology "Victor Babes", Craiova, Romania \\ ${ }^{3}$ Public Health Department Dolj, Romania
}

\begin{abstract}
Long regarded as a hospital-associated and antibiotic use infection, Clostridium difficile infection (CDI) has seen an increasing incidence as a community-aquired infection over the last decade.

Objectives. The paper follows the particularities of CDI with a community onset, depending on the community or nosocomial origin of the infection.

Material and method. Three-year retrospective study (July 1, 2014 - June 30, 2017) of 767 confirmed cases with primary CDI, hospitalized in medical units in Dolj county (România). Two groups of patients with community-onset CDI were analyzed: CA-CDI group with community origin of the infection, and NA-CDIc group with nosocomial origin.

Results. CDI with community onset was identified in 453 patients (59.1\% of the total); of these, $106(23.4 \%)$ had community origin (CA-CDI) and 305 (67.3\%) nosocomial (NA-CDIC). CA-CDI has increased from $4.3 \%$ (2014) to $17.9 \%$ (2017) of the total CDI, with an average of $13.1 \%$ for the study period. Compared to hospitalacquired CDI, patients with community-acquired infection were younger (median age 57 years vs 65 years), more frequently women $(58.4 \%$ vs $46.2 \%)$, with lower exposure to antibiotics $(75.4 \%$ vs $85.9 \%)$, lower associated immunodepression $(4.7 \%$ vs $18.6 \%)$ and mortality $(0.9 \%$ vs. $5.5 \%)$.

Conclusions. CDI epidemiology is dynamic, the actual size of community infection requiring further assessment. CA-CDI should be considered in the investigation of community diarrhea, even in the absence of traditional risk factors (hospitalization, advanced age, antibiotic treatment.
\end{abstract}

Keywords: Clostridium difficile, infecţie comunitară, epidemiologie

\author{
ABBREVIATIONS \\ CDI: Clostridium difficile infection \\ CA-CDI: Community-acquired C. difficile infection \\ NA-CDI: Nosocomial-acquired $C$. difficile infection \\ NA-CDIc: Nosocomial-acquired $C$. difficile infection with communitary onset \\ NA-CDIh: Nosocomial-acquired $C$. difficile infection with hospital onset \\ U-CDI: Undeterminated $C$. difficile infection
}

\section{INTRODUCTION}

Clostridium difficile was originally described in 1978 as an etiological agent in antibiotic-associated diarrhea, and subsequently became a major cause of infectious diarrhea in hospitalized patients (1).
In the past decade, there have been significant changes in C. difficile infection (CDI) epidemiology, with community cases occurring in people without traditional risk factors: over the age of 65 , hospitalization or exposure to antibiotics (2-5). Data from North America and Europe suggest that 
$20-27 \%$ of the CDI are community-based forms, with a rising incidence that may pose a major threat to public health (6).

Increased incidence may be associated with the occurrence in the community of $C$. difficile hypervirulent strains (7), prescription of antibiotics or high diagnose suspicion in medical consultations (3).

Molecular epidemiology of $C$. difficile is dynamic, recent studies demonstrating a large genetic diversity of the identified strains and sources of infection. The ribotype 27 / protein profile NAP1 (isolated in 2005 as the hospital epidemiogenic strain) along with the ribotype 078 (originally identified in swine and cattle) and the novel atypical strains are currently the most incriminated in the community-acquired $C$. difficile infection (CACDI) (8).

Although CA-CDI has generally been characterized as a mild illness, it can be associated with complications, severe evolution and relapses. In a study performed in patients with CA-CDI, 40\% required hospitalization, $20 \%$ had a severe form, $4.4 \%$ severe complications and $28 \%$ had recurrences (9).

Given the implications that the CA-CDI may have in the future for public health, in this study we have been following:

- the evolution of CDI cases with community onset and

- CDI risk factors particularities depending on the community or nosocomial origin of the infection.

\section{MATERIAL AND METHOD}

\section{Definitions}

Criteria for confirming the diagnosis of CDI included: diarrhea ( $\geq 3$ unformed stools in a 24-hour period), a positive laboratory test for the presence of $C$. difficile toxin A and / or B in the stool (using the immunoenzymatic method), without any other cause of diarrhea $(10,11)$.

By location/circumstances acquired, CDI can be classified into 3 types (10-12):

- Nosocomial-acquired CDI (NA-CDI) occurring after 48 hours from admission or within the first 4 weeks after the patient had been discharged from a healthcare facility. CDI can be classified as having hospital-onset (NA-CDIh) or community-onset (NA-CDIc).

- Community-acquired CDI (CA-CDI) occurring within the first 48 hours of admission or if the patient had not been discharged from a healthcare facilty 12 weeks prior to the onset of the symptoms.

- Undeterminated CDI (U-CDI) if the patient had been discharged from a healthcare facility within the previous 4-12 weeks.

\section{Material}

Three year retrospective study (July 1, 2014 June 30, 2017) of 767 primary CDI confirmed cases, hospitalized in medical units in Dolj county (România).

Demographic data (age, gender, urban/rural area), onset of diarrhea (during hospitalization or after discharge), hospital date of admision (year, semester), type of CDI (NA-CDI, CA-CDI, UCDI), risk factors (antacid medication, antibiotic administration, immunodepression, contact with a known case of CDI) and evolution were ascertained from CDI records.

\section{Data analysis}

We followed two CDI groups with communityonset of the symptoms:

- Group A (106 cases) consisting of patients with CA-CDI who did not have hospitalization as a risk factor.

- Group B (305 cases) consisting of patients with NA-CDIc whose onset was within the first 4 weeks after the patient had been discharged from a healthcare facility.

The comparative analysis of the two groups used the median determination and the Chi-squared test (considered statistically significant if $\mathrm{p}<0.05$ ).

\section{RESULTS}

\section{Case distribution by place of onset and type of CDI}

The distribution by type of CDI was as follows: 619 NA-CDI cases, 106 CA-CDI cases and 42 UCDI cases. NA-CDI had a hospital onset in 314 cases and community onset (in the first 4 weeks after discharge) in 305 cases (Fig. 1). 


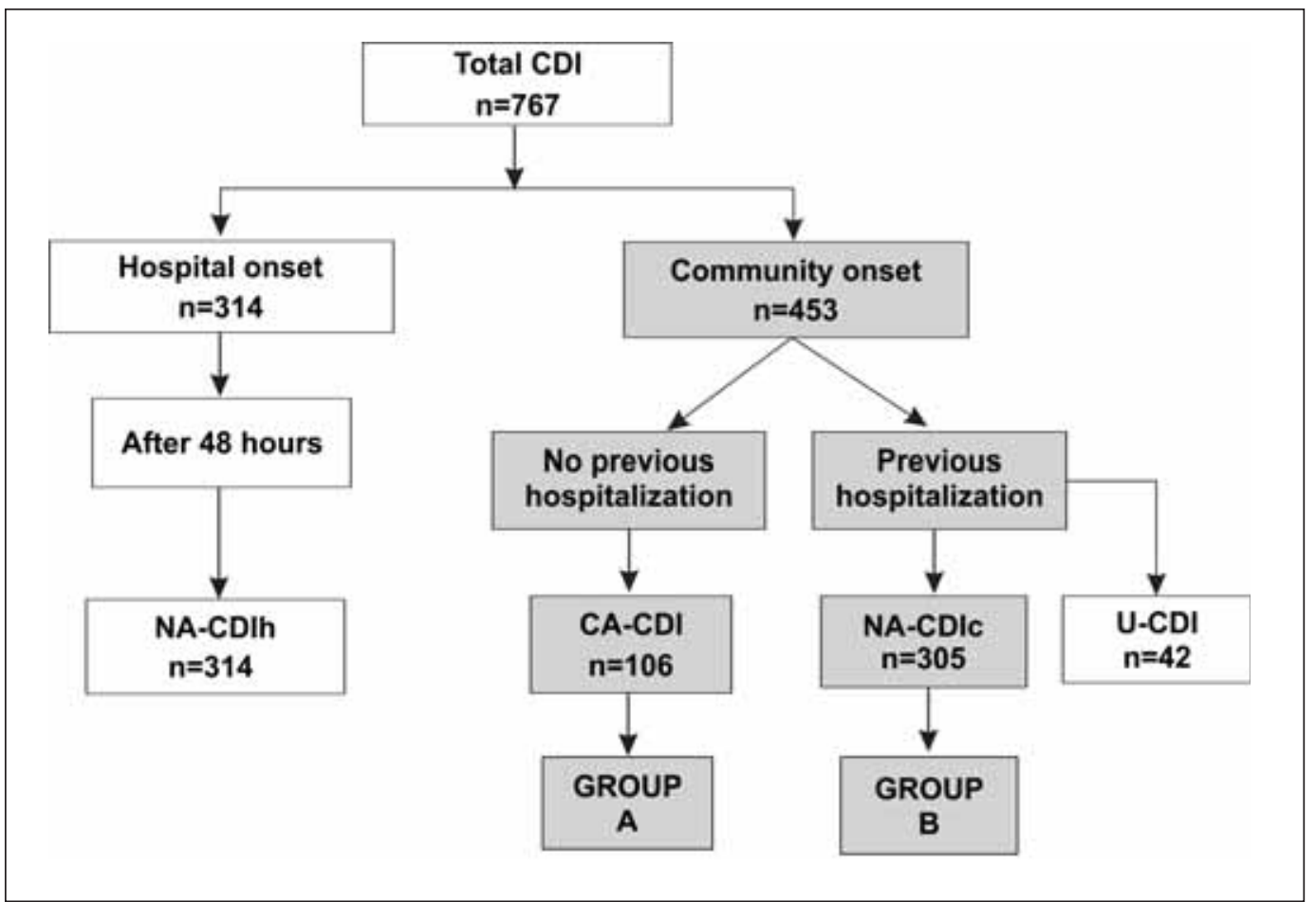

FIGURE 1. Case distribution by place of onset and type of CDI

CDI had a community onset in 453 cases (59.1\% of total) and hospital onset in 314 cases ( $40.9 \%$ of the total), with a statistically significant difference $(\mathrm{p}=0.001)$. Of the 453 cases with community onset, 106 (23.4\%) were patients who had a community origin of infection (CA-CDI), 305 (67.3\%) were patients with nosocomial CDI (NA-CDIc) and $42(9.3 \%)$ had an undetermined cause (symptoms onset within 4-12 weeks after discharge).

\section{Evolution of community-based CDI cases}

In the yearly evolution, represented on a halfyearly basis (Fig. 2), there was a 2.4 times increase in the number of cases of CA-CDI in the first half of 2017 compared to the same period in 2016.

NA-CDIc increased significantly over the study period, from 18 in the second half of 2014 to 106 in the first half of 2017. The total number of CDI cas-

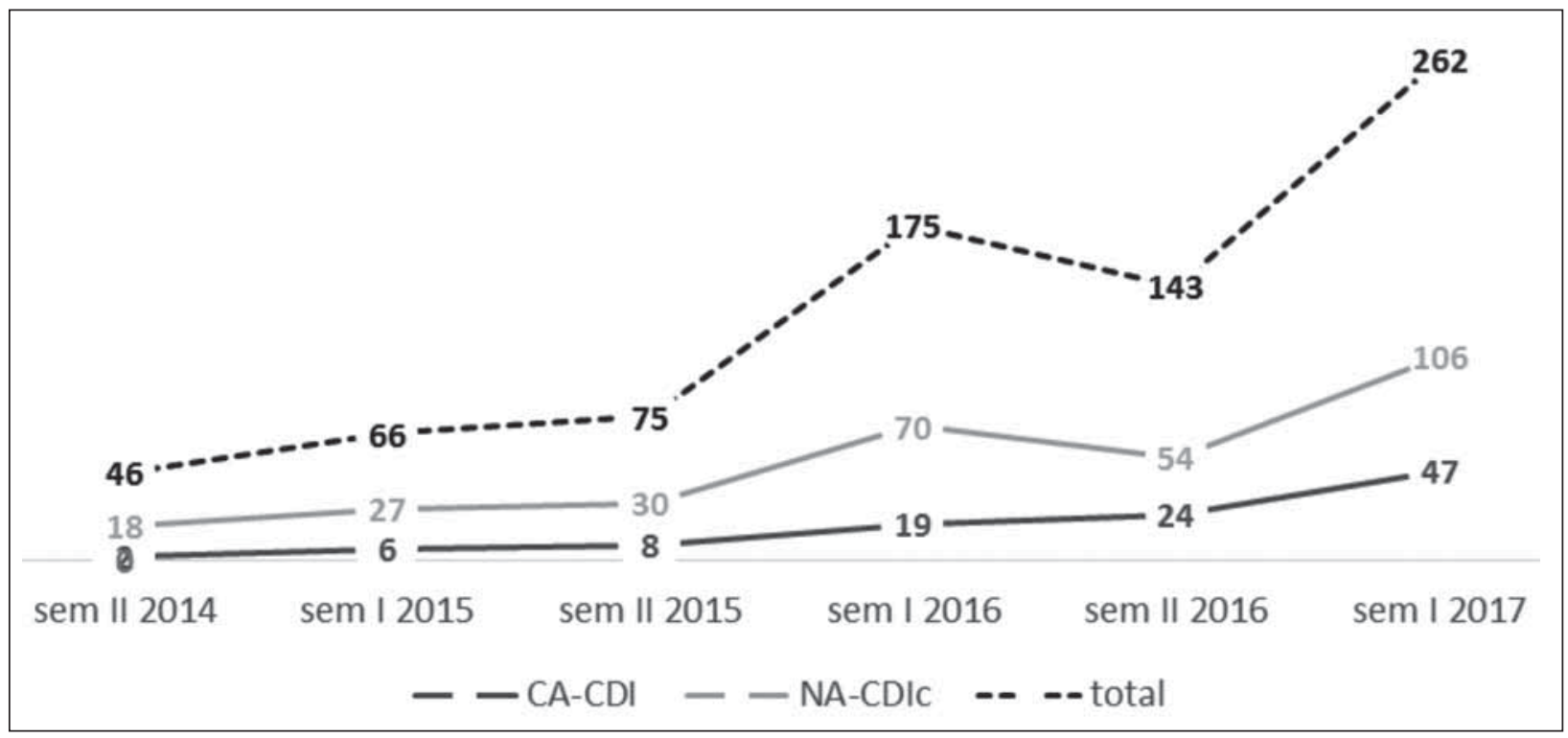

FIGURE 2. The annual and half-yearly evolution of CA-CDI, NA-CDIC and total CDI 


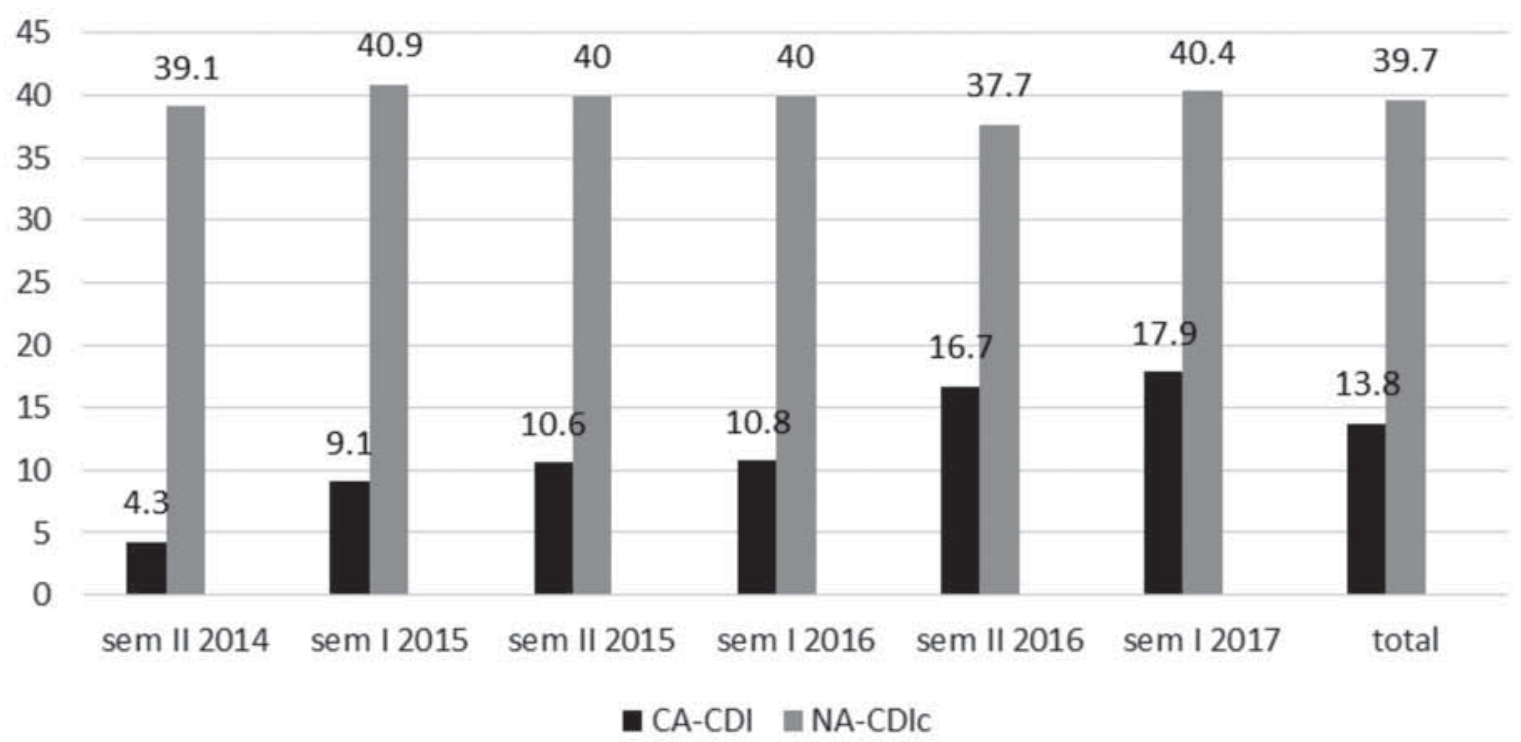

FIGURE 3. Percentage distribution of CA-CDI and NA-CDIC of total CDI

es increased steadily, with the highest value in the first half of 2017 (262 cases).

CA-CDI accounted for $13.8 \%$ of the total CDI in the study period, with a significant increase from $4.3 \%$ in 2014 to $17.9 \%$ of the total CDI in 2017 (Fig. 3). The NA-CDIc did not show significant changes, registering a value between 39.1 and $40.9 \%$ of the total CDI.

\section{Risk factors associated to CA-CDI and NA-CDIc}

TABLE 1. Characteristics of CA-CDI patients versus NA-CDIc patients

\begin{tabular}{|l|c|c|c|}
\hline Characteristics & $\begin{array}{c}\text { GROUP A } \\
\text { (CA-CDI) } \\
\text { (N=106) }\end{array}$ & $\begin{array}{c}\text { GROUP B } \\
\text { NA-CDIc } \\
\text { (N=305) }\end{array}$ & p \\
\hline Age > 60 - N (\%) & $51(48.1)$ & $198(64.9)$ & 0.002 \\
\hline Median age (years) & 57 & 65 & \\
\hline Women - N (\%) & $62(58.4)$ & $141(46.2)$ & 0.02 \\
\hline Urban area - N (\%) & $58(54.7)$ & $156(51.1)$ & 0.52 \\
\hline $\begin{array}{l}\text { Contact with a CDI case - } \\
\text { N (\%) }\end{array}$ & $8(7.5)$ & $106(34.7)$ & 0.001 \\
\hline An bio c treatement - N (\%) & $80(75.4)$ & $262(85.9)$ & 0.01 \\
\hline Immunodepresion - N (\%) & $5(4.7)$ & $57(18.6)$ & 0.005 \\
\hline Antacid medica on - N (\%) & $33(31.1)$ & $97(31.8)$ & 0.89 \\
\hline Deaths - N (\%) & $1(0.9)$ & $17(5.5)$ & 0.04 \\
\hline
\end{tabular}

Median age was lower for CA-CDI patients (57 years) compared to NA-CDIc (64 years), with a significantly higher percentage of patients over 60 years of age in group B (64.9\% of cases) compared to group A ( $48.1 \%$ of cases $)-p=0.002$.

Women recorded a higher percentage in group $\mathrm{A}$ (58.4\%) compared to group B $(46.2 \%)-p=0.02$, with no differences regarding the rural/urban area.
Contact with a known case with CDI was more frequent in group B (34.7\%) at which the infection was hospital-acquired, compared with a small percentage $(7.5 \%)$ of cases from group A where the infection was community-aquired $(p=0.001)$.

Administration of antibiotic therapy was a significant risk factor for the onset of CDI, with more than $75 \%$ of the subjects being reported in both groups.

Antibiotic treatment $(85.9 \%$ vs $75.4 \%)-\mathrm{p}=$ 0.01 and immunodepression (18.6 vs $4.7 \%)-p=$ 0.005 were associated in a higher proportion with patients with prior hospitalization from group B (Table 1).

Antacid medication was administered to $31.1 \%$. respectively $31.8 \%$ of patients in the studied groups, with no statistically significant difference.

Mortality was higher in group B (5.5\%) compared to group A $(0.9 \%)$, with more severe evolution in patients hospitalized for previous disorders $-\mathrm{p}=0.04$.

\section{DISCUSSIONS}

CDI has long been considered as a hospital-associated infection, with a low risk of occuring in community. In a study carried out in Spain, Alcalà L. et al. found that CDI was under-diagnosed in diarrheal disease due to the use of low sensitivity laboratory techniques (19\% of cases) or to the lack of clinical suspicion, especially in younger patients or community-acquired diarrhea (47.6\% of cases) (13). 
Recent reports have provided data on emerging CDI in non-hospitalized patients $(2,5,14,15)$ that require rethinking the approaches for diagnosis, treatment and prevention (16).

In Europe, in a multicentre study based on hospitalized cases from 97 hospitals in 34 countries, CA-CDI showed significant differences ranging from $0 \%$ to $82 \%$ (mean 14\%) (17).

In our study, $59.1 \%$ of CDI cases presented the onset of symptoms in a community setting, but only $13.1 \%$ of cases were CA-CDI. Over the study period, the CA-CDI cases increased, from $4.3 \%$ in 2014 to $17.9 \%$ of the total CDI in 2017. Data reported in North America and Europe show that 20$27 \%$ of CDI cases are community associated, with an incidence of 20-30/100,000 inhabitants $(5,6)$. In a US study by Khanna et al (4), $41 \%$ of CDI cases were community- acquired. with an increased incidence in both inpatients and outpatients (5.3 times for CA-CDI and 19.3 times for NA-CDI). During the study period, healthcare associated CDI cases with community-onset (group B) had a significant share (67.3\%). Concerning this issue, people in the community exposing to $C$. difficile disseminated by dispensed patients, raises the hypothesis of a link between nosocomial and community infection (6).

As demographic particularities, we noticed that patients with CA-CDI had a lower median age (57 years vs 65 years) compared to NA-CDIc and the majority of patients were females $(58.4 \%$ vs. $46.2 \%$ ), with no significant differences regarding urban/rural areas.

CA-CDI studies revealed a median age of 51 years $(4,18)$, lower than NA-CDI $(6)$, affecting all age groups in the community, including young adults and the pediatric population (19). The likelihood of females being more affected in community-acquired infections compared to the nosocomial infections, was also observed by other authors $(4,9,20)$, a possible explanation being the more frequent solicitation of antibiotics in primary care (4) and women caring for young children $(6,17)$.

Contact with a CDI case was reported in $34.7 \%$ of group B patients and only $7.5 \%$ of group A patients, indicating the difficulty of identifying sources of infection in the community. In addition to symptomatic individuals, important sources of infection in community are asymptomatic carriers
(6), but also zoonotic transmission through food (6, $17)$ or contact with children under 2 years of age $(5,19)$ colonized with $C$. difficile toxigenic strains.

Exposure to antibiotic therapy is recognized as the most important risk factor for CDI (17). In our study, antibiotic treatment was administered in $75 \%$ of CA-CDI cases and $85.9 \%$ of NA-CDIc patients. A study performed in Mayo Clinic (US) showed that patients with CA-CDI had a lower exposure to antibiotics than those who acquired the infection in hospital (78\% versus 94\%) (4).

In addition to antibiotics treatments, the increase in prescription of antacid medication in outpatient treatments is also responsible for CA-CDI emergence. The role of antacid medication remains controversial, (21) in our study, there being no significat difference between CA-CDI and NA-CDIc patients (31.1\% versus $31.8 \%$ ). Some studies have shown a 1.6 to 1.7 -fold increase in the relative risk for CDI by administering antacids $(22,23)$, but the the role of this medication is not yet clear, associating antacid medication and antibiotic being related to increasing CDI risk in hospitalized patients (24).

Mortality rate recorded significant differences between CA-CDI and NA-CDIc $(0.9 \%$ vs $5 \%)$, correlated with a higher percentage of CDI-associated severe comorbidities in hospitalized patients (immunodepression in $18.6 \%$ of patients in group B versus $4.7 \%$ in group A). Khanna S. (4) observed in a study in CDI patients that community-acquired infections had a lower comorbidity score and the pregression to severe forms was lower (20\% vs. $31 \%$ ) compared to hospital-acquired infections. Although CA-CDI may be considered benign, in the future, risk factors for severe progression may be associated with an increase in corticosteroid and immunosuppressive therapy, inflammatory bowel disease, kidney disease, neoplastic disease, or diabetes (25).

\section{CONCLUSIONS}

Epidemiology of CDI, long considered as a healthcare associated infection, is dynamic and may raise new issues related to community shifting.

Of the total CDI, a substantial fraction had a community onset, the incidence of both, community and nosocomial infections increasing over time. Since the CA-CDI cases included only inpa- 
tients in our study, the actual size of the community infection requires further assessment.

Demographic particularities of CA-CDI in our study were related to the lower mean age and the higher incidence in women compared to NA-CDIc. Among the risk factors analyzed, antibiotic treatment was strongly associated with the development of CDI, in both community and nosocomial acquired.

The absence of traditional risk factors (over 60 years of age, hospitalization, antibiotic treatment) does not exclude CDI and testing of this condition should be taken into consideration in the investigation of community diarrhea.

Conflict of interest: none declared Financial support: none declared

\section{REFERENCES}

1. Olson D., Scobey M. The Challenge of Clostridium difficile Infection. NCMJ. 2016; 77 (3): 206-10

2. Centers for Disease Control and Prevention (CDC). Severe Clostridium difficile-associated disease in populations previously at low risk - four states. MMWR. 2005; 54(47): 1201-5

3. Khanna S., Pardi D.S. The growing incidence and severity of Clostridium difficile infection in inpatient and outpatient settings. Expert Rev Gastroenterol Hepatol. 2010; 4(4):409 -16

4. Khanna S., Pardi D.S., Aronson S.L. et al. The epidemiology of community-acquired Clostridium difficile infection: a population-based study. Am J Gastroenterol. 2012; 107(1):89-95

5. Wilcox M.H., Mooney L., Bendall R. et al. A case-control study of community-associated Clostridium difficile infection. J Antimicrob Chemother. 2008; 62 (2):388-96

6. Gupta A., Khanna S. Community-acquired Clostridium difficile infection: an increasing public health threat. Infect Drug Resist. 2014; 7: 63-72

7. Juneau C., Mendias E.P., Wagal N. et al. Community-Acquired Clostridium Difficile Infection: Awareness and Clinical Implications. J Nurse Pract. 2013; 9(1): 1-6

8. Bignardi G.E., Settle C. Different ribotypes in community-acquired Clostridium difficile. J Hosp Infect. 2008; 70(10): 96-8

9. Khanna S., Pardi D.S., Aronson S.L. et al. Outcomes in community acquired Clostridium difficile infection. Aliment Pharmacol Ther. 2012; 35 (5): 613-18

10. Centrul Național de Supraveghere și Control al Bolilor Transmisibile. Metodologia de supraveghere a infecției cu Clostridium difficile; accesat la adresa [http://www.cnscbt.ro/index.php/metodologii/ infectii-nosocomiale/194-metodologie-supraveghere-icd-2014/file]

11. Cohen S.H., Gerding D.N., Johnson S. et al. Clinical practice guidelines for Clostridium difficile infection in adults: 2010 update by the society for healthcare epidemiology of America (SHEA) and the Infectious Diseases Society of America (IDSA). Infect Control Hosp Epidemiol. 2010; 31 (5):431-55

12. McDonald L.C., Coignard B., Dubberke E. et al. Recommendations for surveillance of Clostridium difficile-associated disease. Infect Control Hosp Epidemiol. 2007; 28(2):140-5

13. Alcala L., Martin A., Marin M. et al. The undiagnosed cases of Clostridium difficile infection in a whole nation: Where is the problem? Clinical Microbiology and Infection. 2012; 18 (7):205-15 diarrhea and Clostridium difficile in the community. Aliment Paharmacol Ther. 2003; 17(70):905-12

15. Frost F., Hurley J.S., Petersen H.V. Estimated incidence of Clostridium difficile infection. Emerg Infect Dis. 1999; 5(2):303-4

16. Vindigni S.M., Surawicz C.M. C. difficile Infection: Changing Epidemiology and Management Paradigms. Clinical and Translational Gastroenterology. 2015; 6: e99

17. Bloomfield L.E., Riley T.V. Epidemiology and Risk Factors for Community-Associated Clostridium difficile Infection: A Narrative Review. Infect Dis Ther. 2016; 5(3): 231-51

18. Chitnis A.S., Holzbauer S.M., Belflower R.M. et al. Epidemiology of community-associated Clostridium difficile infection, 2009 through 2011. JAMA Intern Med. 2013; 173(14):1359-67

19. Khanna S., Baddour L.M., Huskins W.C. et al. The epidemiology of Clostridium difficile infection in children: a population-based study. Clin Infect Dis. 2013; 56 (10):1401-6

20. Fellmeth G., Yarlagadda S., lyer S. Epidemiology of community-onset Clostridium difficile infection in a community in the South Of England. Journal of Infection and Public Health. 2010; 3 (3):118-23

21. Khanna S., Aronson S.L., Kammer P.P. et al. Gastric acid suppression and outcomes in Clostridium difficile infection: a population-based study. Mayo Clin Proc. 2012; 87 (7):636-42

22. Janarthanan S., Ditah I., Adler D.G., Ehrinpreis M.N. Clostridium difficile-associated diarrhea and proton pump inhibitor therapy: a meta-analysis. Am J Gastroenterol. 2012; 107(7):1001-10

23. Kwok C.S., Arthur A.K., Anibueze Cl. et al. Risk of Clostridium difficile infection with acid suppressing drugs and antibiotics: meta-analysis. Am J Gastroenterol. 2012;107(7):1011-9

24. Stevens V., Dumyati G., Brown J., Wijngaarden E. Differential risk of Clostridium difficile infection with proton pump inhibitor use by level of antibiotic exposure. Pharmacoepidemiol Drug Saf. 2011; 20(10): 1035-42

25. Furuya-Kanamori L., Stone J.C., Clark J. et al. Comorbidities, Exposure to Medications, and the Risk of Community-Acquired Clostridium difficile Infection: a systematic review and meta-analysis. Infect Control Epidemiol. 2015; 36 (2): 132-41
14. Beaugerie L., Flahault A., Barbut F. et al. Antibiotic-associated 